\title{
Job Creation Strategies for Nigeria
}

\author{
Onuoha, Peripaul Oluchukwu and Woghiren, Uhunoma \\ Economics, University of Lagos, Nigeria $(+234) 8089128986$ \\ Email: peripaulonuoha@gmail.com
}

\begin{abstract}
This paper attempts to survey a wide range of job creation strategies that policymakers can implement during times of economic recession. This paper does not attempt to determine which job creation strategies work "best;" rather, it is a broad survey mapping the landscape of job creation strategies. We organize the strategies in this paper around four broad categories. Many of the strategies we discuss serve more than one of these categories; taken, they all can contribute to stabilizing the economy and adding net new jobs, if implemented appropriately. While strong economies have the luxury of concentrating on long-term job growth and labour supply strategies, the Recession as currently experienced in Nigeria requires government practitioners to focus more narrowly on stimulating labour demand and employing workers now. Practitioners must balance long and short-term goals in job creation, realizing that few policies can serve both.
\end{abstract}

Keywords: Job creation, small businesses, green jobs, economic development, business financing, employment, business incubators, infrastructure, unemployment.

\section{Introduction}

Nigeria is one of the fastest growing economies in Africa, with average GDP growth rate of between 5\% and $6 \%$ between 2000 and 2011. This trend in growth continued till in 2016 when the economy plunged into recession. This growth has happened together with structural transformation; however, it has not translated into a reduction in rate of unemployment; ironically unemployment surged from about $11 \%$ in 2000 to over $23 \%$ in $2011[1]$.

The government of Nigeria has put in place various policy measures to reverse this. It introduced policies to reform the restrictive investment climate that dominated the period between 1962 to the return to democracy in 1999 which ushered in private sector led growth strategy. Recent policy measures that support this include the National Economic Empowerment Development Strategy (NEEDS) adopted in 2003. NEEDS gave way to Vision 20:2020 of 2009 which inspired successive National Development Plans and the Transformation Agenda of 2011-2015. The latter, among others, made economic development and inclusive growth its overarching development agenda which made job creation an integral part of sector level reforms. In addition, programs managed by the Federal Government level, aimed at supporting job creation were introduced. This included, inter alia, the Subsidy Re-investment and Empowerment Program (SURE-P), which comprised Community Service Scheme and Graduate Internship Scheme; and the Youth Enterprise with Innovation in Nigeria (YouWiN!) program, which comprised the Conditional Cash Transfer (CCT), vocational Training, Public Works and Science and Technology.

The latest federal government job creation effort is the Social Investment Programme, popularly known as the Npower programme. In this programme, graduates are exposed to materials, resources and videos that will help them develop skills \& build competencies to excel in the Labour market. This program is believed to improve the employability or entrepreneurial skill set of each volunteer. They will be able to access content from a variety of sources to build life essential skills such as: (1) Entrepreneurship, (2) Employability \& Work Readiness, (3) Financial Literacy, and (4) Management Skills

While strong economies have the luxury of concentrating on long-term job growth and labour supply strategies, the Recession as currently experienced in Nigeria requires government practitioners to focus more narrowly on stimulating labour demand and employing workers now. Practitioners must balance long and short-term goals in job creation, realizing that few policies can serve both. 


\section{What is Meant by 'Job Creation'?}

Job creation is difficult to evaluate because it is difficult to measure. This paper attempts to survey a wide range of job creation strategies that policymakers can implement during times of economic recession. The proverbial golden egg of job creation policies is the "net new job"- the job that is created without displacing any other economic activity. While it is easy enough to measure whether a new job has been created at the macroeconomic scale by looking at aggregate data from the National Bureau of Statistics, it is very difficult to determine if (1) the jobs created didn't merely displace jobs in other locations or sectors, and (2) if the jobs were created because of a specific policy. Throughout this paper, this dilemma emerges frequently; the theoretical mechanism for how a policy creates jobs may be well understood, but data showing that it did create net new jobs are ambivalent at best or, more commonly, simply non-existent.

This paper does not attempt to determine which job creation strategies work "best;" rather, it is a broad survey mapping the landscape of job creation strategies. We organize the strategies in this paper around four broad themes. The first theme, "Macroeconomic Strategies" looks at macroeconomic strategies that promote net new job creation. These strategies may help create jobs at the aggregate level, but we believe they fall short on several levels. Principally, macroeconomic job creation does not address how job growth happens unequally across geographic locations, industry sectors, and worker populations. To address this, the other three themes in this paper describe more focused job creation strategies. The second theme discusses place-based job creation strategies, such as business attraction and enterprise zones. The third theme looks at business-based strategies that attempt to create jobs in certain business types or industries, such as green jobs and small businesses. The final theme describes worker-based strategies that address job quality and targeting jobs for disadvantaged workers. These strategies include local hire policies and high road agreements. Many of the strategies we discuss serve more than one of these themes; taken, they all can contribute to stabilizing the economy and adding net new jobs, if implemented appropriately.

This policy paper performs a broad literature review to gather different strategies and present the advantages and disadvantages of each strategy. While no strategy serves as a panacea for job creation, we hope this paper serves as a sort of road map for practitioners to help guide their way through the vast array of strategies available.

\section{Federal- and State-Level Strategies}

Macroeconomic and other high-level job creation strategies in Nigeria usually entail action by the federal and state government. Most federal policies are broad policies and involve disbursing money to the state and local level for certain job creating activities. Similarly, states will sometimes act as a disburser of funds to the local government level.

Federal job creation strategies have the advantage that only the federal government can print money and operate under a budget deficit-giving the federal government more room to manoeuvre fiscally, while states are constrained by their budgets. Much of this federal money trickles down to state and local levels through grants and aids, where most implementation-related details are handled.

There are four primary ways in which the federal government can influence job creation: interest rate reductions, government hiring and purchases, transfer payments, and tax credits [2]. The effectiveness of strategies depends on the economic environment of the nation, and hence not every strategy applies for every economic situation. The following are job creation strategies commonly applied at the state and/or federal levels:

\subsection{Interest Rate Reductions}

The federal government lowers interest rates in the short-term economy through open market operations (OMO), that is, the sale and purchase of securities such as government treasury bills and bonds. Purchases of securities through OMO lower the Monetary Policy Rate (MPC) and in turn will lower the real interest rate. Such reductions in interest rates alter borrowing costs and make private investments cheaper, thus serving as an incentive for companies to invest in capital, hire more workers, and grow the 
economy. They also boost consumption further because of the income gains that result from the higher level of economic output.

Advantages

Job Creation through Markets. As consumption and business investment spending is sensitive to interest rates, lowering interest rates will allow for greater spending and investments in the market. It allows investments to flow to the most productive sectors instead of letting government choose "winning industries" through subsidies.

Fast Implementation. Interest rate reductions are also easy to implement since they do not involve any legislative action.

Disadvantages

Capital Investments over Jobs. Lowering the interest rates serves as an incentive for companies to invest more. However, that could take the form of capital investments, not necessarily new jobs creation.

Limited Effectiveness. Once the Monetary Policy Committee lowers their rates to zero, they have exhausted their primary option to affect job creation and stimulate the economy.

Increased Inflation. Lowering the MPR will have an adverse effect of increasing inflation by increasing the money supply in the economy.

\subsection{Government Hiring and Purchases}

Government hiring, and purchases create jobs either through direct hiring of government employees (i.e the federal government Npower programme) or indirectly through government purchasing activities. Because of the federal government's ability to operate at a deficit, continued government employment can have a significant positive multiplier effect. The effect varies depending on the exact type of spending [3].

Continued employment can also reduce unemployment as fewer people need to be reabsorbed into the labour market. As economist Ken Jacobs says, "The best way to create jobs is to not kill existing jobs" $[4]$.

The additional government spending through Npower allowed for more than just continued employment to stimulate further job creation. This section will reveal government hiring and purchases through the lens of infrastructure.

\subsubsection{Infrastructure investments}

While there is much debate about whether government spending "crowds out" private spending, infrastructure is an area where crowding out should be of little concern [5]. Crowding out refers to the reduction of private investment due to government spending. Investing in infrastructure, by building roads and water systems and the like, creates jobs in the short term, while investing in infrastructure such as public transit systems and electrical grids will employ workers for multiple periods and can create jobs in the long-term. There can also be a cost advantage to building infrastructure during a recession, as construction bids tend to be lower than normal. Thus, infrastructure is a valuable countercyclical tool in creating jobs during a recession [6].

Advantages

Short-Term Job Creation. Many projects are at a standstill due to the lack of funding. For "shovel-ready" projects that have been approved but previously lacked funding, the recession creates opportunities for implementation, thereby creating jobs immediately.

Long-Term Job Creation. Infrastructure investments ease the cost of doing business and increase indirect jobs in the long run through the private sector [5].

Disadvantages

Few Domestic Suppliers. Nigeria is currently not set up to make most infrastructure purchases domestically which means that the Nigerian economy will not reap the full job creation benefits from infrastructure investments. For example, most bridge construction supply manufacturers are European, benefitting European workers when Nigeria invests in infrastructure. To stimulate more job creation, investment in infrastructure must also be accompanied by policies to build the domestic supplier base for infrastructure, as these will be manufacturing jobs for middle and low-skill workers. 


\subsubsection{Development Bank of Nigeria (DBN): targeted financing}

Despite that infrastructure investments are in high demand and can create jobs, the current political structure impedes these investments. A Development Bank (DB) is a targeted mechanism for financing infrastructure that balances rate-of-return goals with multiple policy goals. The ability for a DB to incorporate multiple policy goals in their rate of return calculation can encourage projects that promote job creation, entrepreneurship, equitable job opportunities, green infrastructure investment, and necessary infrastructure maintenance. Using a DB also reduces disintegrated pet projects and offers a more holistic approach to infrastructure needs and the Nigerian policy goals.

\subsubsection{Transfer payments}

Transfer payments create jobs indirectly through the spending patterns of those receiving the transfer payment, creating a multiplier effect. Two key programs that stimulate indirect job creation are shorttime compensation programs and worker subsidies.

\section{Place-Based Strategies}

\subsection{Business Attraction \& Retention}

Local governments attempt to create a friendly business climate through incentives because some supply-side theories assert firms will locate where they can minimize costs, thus increasing local employment.

Business attraction strategies represent the first wave of economic development practice, where localities attempted to target firms with offers of cash or near-cash assistance, in the form of subsidized loans and tax exemptions, to encourage their relocation [7]. Business retention strategies are part of second-wave economic development that focuses on getting information on the needs of local businesses, and then encouraging government actions to better meet those needs and increase local benefits. Retention programs range from business visitation and surveying programs, to planned manufacturing regions and business clusters.

Business incentives can be controversial, as they are vulnerable to criticism by liberals as "corporate welfare" for business and by conservatives as government interference in the private sector [8]. In theory, providing benefits and assistance to businesses can result in increased local jobs when these new and expanding businesses add to the local economy's export base or substitute for imports. Growth also comes from multiplier effects generated by expanding businesses' local suppliers, and increased worker income leading to growth in local retailers and services.

Job chain theory builds on the idea that business growth generates jobs by positing that, as an industry expands, new staff positions are created throughout the jobs ladder, allowing mid-and low-level workers to move up the chain and eventually opening opportunities that reach low-skilled, unemployed people [9].

In the long run, incentives and assistance for businesses should increase labour demand by providing more jobs and/or improving jobs quality; but in the short run, there may be little effect on new jobs and even a decrease as demand shifts toward higher-productivity jobs [8]. This leads experts such as Timothy Bartik to argue for a focus not on job growth as the goal but rather higher earnings per capita. In any case, though business incentives are still widely used, localities may be gradually shifting away from these strategies [10].

Examples of widely used business attraction and retention strategies include the following.

\subsubsection{Provision of local economic data}

Local economic development organizations often attempt to provide good information and assistance with permits and zoning regulations for business prospects. This may affect large companies that are seeking to get a plant into operation quickly, as well as small businesses that need help navigating red tape at city hall. Providing reliable information on sites, business entry requirements and helping overcome problems with permits and regulations can help create jobs by attracting business prospects and saving start-up time.

\section{Advantages}

Information Access. This allows for job creation by giving businesses more information about comparative advantages of a locality that they may otherwise be unaware of. 
Cost-Effective. Providing basic information to businesses requires relatively modest expenditures of economic development staff.

Transparency and Accountability. Streamlining and providing transparency for information access on economic development activities helps increase public accountability.

\section{Disadvantages}

Lack of Impact and Measurability. The effect on actual business location decisions and, by extension, potential job creation is likely to be small and not well-measured quantitatively.

\subsubsection{Marketing}

Marketing efforts play a significant role in job creation strategies by emphasizing a locality's comparative advantages over its competitors.

Surveys of economic development directors have found that they define sales activities as the most frequent and important activity their office engages in [11]. Marketing of tourist centres also has spurred a large site consulting industry, which is used by more large corporations to make location decisions.

Localities' marketing activities include preparing promotional materials, developing websites featuring the community's advantages for businesses, tourist centres, networking with business prospects, and advertising.

\section{Advantages}

Improved Efficiency. All this marketing activity results in dissemination of more information about business location issues, which arguably increases efficiency in the allocation of resources.

Cost-Effective. Though time-consuming, sales activities may be more cost-effective since they focus on relationship building to attract businesses and not financial subsidies.

\section{Disadvantages}

Zero-Sum. At the national level, localities' rival marketing activities can feed into local intergovernmental competition and amount to a zero-sum game, where net new job creation may occur in the locality but not necessarily in the state or the nation.

Information Asymmetry. Marketing efforts fuel the site consulting industry, which may lead to information asymmetries and potential market inefficiency. Also, trade magazines advise firms on strategies to play localities against each other and publicize winners and losers among localities - all feeding into incentive competition [12].

\subsubsection{Creation or retention of industrial zones}

Cities have tried to maintain and grow new business with industrial retention programs that incentivize manufacturing firms to remain (rather than flee to the suburbs) by making the inner city more amenable to manufacturing [13]. Components of these programs include identifying and responding to business needs, creating planned manufacturing districts to prevent competition for land among incompatible uses, and developing industrial parks with city-provided services. More specialized business assistance also can be provided to smaller manufacturers through manufacturing extension programs. These programs provide smaller manufacturers with access to business consulting to improve their productivity through new technologies, workplace management, and business planning and marketing. Assistance is often targeted at smaller manufacturers that need assistance but that also have a significant chance of surviving and providing well-paying jobs if they can increase their productivity.

\section{Advantages}

Retention of Manufacturing Jobs. If cities can utilize land-use planning tools to retain manufacturing, then jobs and increased wages can be provided for residents of the inner city. More effective planning and zoning can help reduce the cost of doing business for manufacturers.

Attracting Local Suppliers. This strategy also could build upon the clustering concept, if local suppliers are attracted or retained because of manufacturing zones, thus increasing jobs regionally.

\section{Disadvantages}

Limited Supply of Land. Finding available land for development is a problem for manufacturers considering locating or expanding in an urban area. There are opportunity costs associated with dedicating scarce central land to industrial uses.

Political Complications. Planned manufacturing districts and industrial zones may face competing interests for land use among city residents, farmers, cattle rearers, developers and businesses.

Regional and Global Competition. Cities in Nigeria continue to lose their traditional agricultural base jobs to suburbs, other regions of the country, cattle rearers, developers and abroad. Globalization 
and trade imbalances lead to significant challenges for developing and retaining manufacturers in Nigeria. A good example is the Dunlop company.

\subsubsection{Tax incentives}

Tax incentives for job creation are used by all states and most localities in some form and constitute the largest share of public resources used in economic development. They include property tax abatements, sales tax exemptions and credits, corporate income tax exemptions, and job tax credits tied to the number of workers hired. As firms become more mobile due to declining transportation and communications costs, state and local government tax policies are one way to affect business costs and influence location decisions [14]. Incentives to attract or retain businesses are therefore justified by proponents as a cost that produces potential benefits of more employment and stronger state and local fiscal situations [14].

Advantages

Effective in Specific Circumstances. Tax incentives can affect business location and expansion decisions if well-designed and targeted to the specific locality. Effective policies often focus on businesses that are at a stage where their development can be affected by policy interventions - such as start-ups and firms facing competitive challenges [15]. Incentives have much larger effects on location decisions among different communities within a metropolitan area than on location decisions among different states or metropolitan areas. Once a company has narrowed its choice of location to a region, the tax burden and physical characteristics of potential sites may have more influence over its decision.

Targeting High-Wage Industries. Incentives can be made more effective by targeting incentives at businesses that pay higher wages, since these industries could drive up local wage standards and increase the net earnings effect for the region; however, such businesses provide few opportunities for more disadvantaged workers.

Clawbacks. Tax incentives can be improved by tying them to contractual restrictions that allow for clawbacks (government recovery from the business of some or all the incentives' value) if certain job and earnings creation goals are not met.

Improving Accountability. Other reform ideas emphasize promoting more public transparency and participation in policymaking, coordinating incentives regionally or on a state level, and conducting cost-benefit analysis of incentive policies [14].

\section{Disadvantages}

Expensive. Tax incentives are a high-cost way of creating jobs, which can outweigh the public benefits they create and redirect resources from public spending on infrastructure and education.

Reduces Resources for Other Public Needs. Some studies find that business tax reductions, if financed by reducing spending on local education or roads, may lower a local economy's employment.

Little Impact on Firm Location Decisions. Evidence indicates that the use of tax incentives may have negligible impact on firms' decisions to locate.

Zero-Sum. To the extent that tax and incentive competition results in a redistribution of jobs, this shifting of jobs has little beneficial effects for the nation and amounts to a zero-sum game.

Destructive Competition. Local government competition through tax incentives may lead to a destructive cycle of stagnating or declining economies, and lower tax bases.

\section{Business- and Sector-Based Strategies}

The following section examines both business- and sector-based strategies that support net new job creation. We focus more specifically on strategies that support small businesses, given their potential to play a significant role in job creation. In addition, we identify strategies within high-growth sectors, specifically the emerging clean energy and green jobs sectors, since certain sectors fared much worse than others in the recent recession.

\subsection{Supporting Small Businesses}

There has been much debate as to whether small businesses create more jobs than large businesses. Much of this debate has centered on David Birch's early research during the late 1970's and 1980's about the impact small businesses have on job creation. We first define what we mean by small business. 
In Nigeria, before the launch of the National Policy on MSMEs in Nigeria in 2007, various institutions have adopted varying definitions according to their perception of the concept.

For a coherent national policy, the standard definition to provide a common object of reference by stakeholders in Nigeria today as contained in the National Policy on MSMEs in Nigeria [16], is adopted in this paper as shown in Table 1. The National Policy document states that, where there exists a conflict in classification between employment and assets criteria (for example, if an enterprise has assets worth seven million naira (N7m) but employs 7 persons), the employment-based classification will take precedence and the enterprise would be regarded as micro. This is because employment-based classification tends to be relatively more stable definition, given that inflationary pressures may compromise the asset-based definition.

Table 1. Classification of MSMEs in Nigeria

\begin{tabular}{lll}
\hline Size Category & Employment & Assets (N million) (excluding land and buildings) \\
\hline Micro enterprises & Less than 10 & Less than 5 \\
Small enterprises & $10-495$ & less than 50 \\
Medium enterprises & $50-199$ & 50 - less than 500 \\
\hline
\end{tabular}

Source: Small and Medium Enterprises Development Agency of Nigeria (SMEDAN), Abuja, 2007

Birch argue that small business account for a disproportionate share of new jobs, asserting that firms of 20 or fewer employees created 88 percent of jobs between 1981 and 1985, and attributed this to the high rate of small start-ups [17]. In response, other researchers suggested his work exaggerated small businesses' impact on job creation, and that most of the long-term job generation occurred among a small number of successful, larger firms. Other critiques further stressed the more significant role large firms played in the U.S. economy by providing most jobs, paying the highest wages, maintaining higher success rates, and being more likely to adopt and implement technology [17].

Given the differing perspectives and contradictory research, we ask, do small businesses create more jobs? [18] study attempts to answer this using updated National Establishment Time Series (NETS) data for jobs and businesses between 1992 and 2004. The study considers gross job creation and gross job destruction figures within a year's period, to find net job creation rates among businesses of all sizes. According to the study, establishments with less than 20 employees had an average $15.2 \%$ net job creation rate, the highest job creation rate among all categories of establishments ranging from 0 $50,000+$ employees.

To account for random measurement errors or transitory employment declines in businesses, [19] applied a more conservative approach that only characterized small businesses if they averaged as small businesses over two years (instead of a single year). With this method, the number of establishments under 20 employees decreased along with their average job creation rate significantly to $2.6 \%$, however it remained the highest job creation rate among all other sizes of establishments.

Their research also points out that while firms under 20 employees had a moderately higher job creation rate, they also had the highest job destruction rate. It's therefore important to understand the dynamics of small businesses and how they contribute to job creation.

Small businesses usually start small, and may grow to reach an optimal size, but remain inherently small over the long-term [18]. Innovation in general is argued to be a key feature of small businesses that supports their creation and sustainability. They argue that high job creation rates among small firms were primarily explained by the birth of new firms.

Furthermore, they acknowledge the type of economic growth that was occurring during 1992-2004, a time when small and innovative technology start-ups played a significant role in the booming Internetbased economy. Thus, births of businesses in this industry contributed substantially to job growth.

In sum, this research finds that small businesses do create more net new jobs, though less than Birch had claimed. Small businesses therefore can be important sources of net new job creation. We turn to specific strategies aimed at creating, sustaining, and growing small businesses that the public sector can implement and/or influence, as measures taken to foster job growth. Strategies include subsidized and low-cost loans and grants, small business financing, and assistance through Bank of Industry, 
Development Bank of Nigeria, Bank of Agriculture, and business incubators. We also examine government stimulated demand for small businesses through mandated procurement policies.

Capital access programs provide low-cost capital to attract and expand businesses through means such as direct loans from co-operative society loan funds, which are among the most common programs that can be supported by local governments. Government loan guarantees to encourage financial institutions to lend to businesses, subsidies to banks' loan loss reserves, and programs to expand availability of venture and equity capital are other forms of financial assistance for businesses.

These programs are generally open to businesses of all sizes, but their per-business impact is greatest when used to finance small business activity.

\section{Advantages}

Addresses Wage Costs. Low-cost capital and credit are key inputs for businesses, along with wage costs. Allowing businesses to borrow will allow them to hire more workers, which represents a significant component of their total costs. Access to capital is one of the biggest challenges firms face today because of banks' tightened lending.

\section{Disadvantages}

Cronyism. Governments may loan capital to corporations based on favouritism, limiting their effectiveness. Grants allow politicians to publicly demonstrate that they are bringing business development to their districts, which play into political pressures to take credit for business attraction.

Subsidizing Private Risk. Subsidies and grants for targeted businesses may also have the effect of reducing activity among other local businesses, and potentially leading risk burdens to be transferred to the public sector.

Lack of Transparency. It is difficult to evaluate the effectiveness of capital market programs because the financial selection process does not provide clear and consistent data.

\section{MSMEs in Nigeria}

By global standards large enterprises are very few in Nigeria. Peasant agriculture predominates, accounting for about $95 \%$ of total agricultural output in Nigeria and employment in the sector [20], while the agricultural sector has been the mainstay of the Nigerian economy and currently accounts for $40.9 \%$ of the country's GDP [20]. It is also estimated that non-farm MSMEs account for over $25 \%$ of total employment and $20 \%$ of GDP in Nigeria [16].

Empirical evidence shows that MSMEs dominate the industrial sector in Nigeria, accounting for about $70 \%$ of industrial employment and $10-15 \%$ of manufacturing output [20]. Available information confirms that informal manufacturing enterprises are dominated by small-size operators in the country, in terms of number of people employed with percentage distribution ranging between 92 and 98 across activity sectors. Furthermore, the contribution of the entire informal sector (agricultural sector inclusive) to the GDP was put at $38.7 \%$ [21]. They have been very prominent in the manufacture of bakery products, leather products, furniture, textiles and products required for the construction industry.

It has been recognized that among the constraints to effective development of MSMEs in Nigeria is the limited access of the investors to long term credit and the general non availability of comprehensive information which can guide potential investors and hence reduce the cost of pre-investment information gathering which may be very high and prohibitive [22] [23] [24] [25] [26] [27).

Government funding schemes for micro, small and medium enterprises in Nigeria

A brief review of both the old and new funding initiatives for MSMEs in Nigeria is presented below (see CBN Briefs, 1992 to 2006 for details).

- The Nigerian Industrial Development Bank (NIDB). The NIDB was established in 1964 and charged with the function of harnessing local and foreign skills and local and foreign private capital in the development of new industries and the expansion of existing ones.

- Small-Scale Industries Credit Scheme (SSICS). The small-scale industries credit scheme was introduced in 1971 as a revolving grant by the federal and state governments to assist in meeting the credit needs of small-scale enterprises on liberal terms.

- Promotion of small-Scale Enterprises. The CBN, from 1970, was instrumental in promoting wholly-owned Nigerian enterprises. In its then Policy Guidelines, the Bank directed that with effect from April 30, 1970; credit to indigenous borrowers was to be at least 35\% of commercial and merchant banks' total loans and advances. The proportion of loans to indigenous borrowers was raised in subsequent years with special emphasis on small-scale enterprises. 
- Promotion of Agricultural and Manufacturing Activities. Through its Monetary Policy Circulars (before its abrogation in 1996), the CBN prescribed that not less than $15 \%$ of commercial and $10 \%$ of merchant banks' credit be granted to agricultural activities. The banks were also to allow grace periods on agricultural loans: one year for small-scale peasant farming, four years for cash crop farming, five years for medium and large-scale mechanized farming and seven years for ranching. To promote manufacturing activities, the Bank stipulated in its guidelines that not less than $35 \%$ of commercial and $40 \%$ of merchant banks' credit be granted to manufacturing enterprises.

- Promotion of Rural Banking. To encourage banking habit nationwide and channel funds into rural development, the CBN introduced the Rural Banking Scheme in June 1977 in three phases-19771980, 1980-1985 and 1st August 1985 through 31st July 1989. As at end-June 1992, 765 of the 766 branches stipulated by the CBN had been opened. Also, the CBN stipulated that not less than $50 \%$ of the deposits mobilized from the rural areas be advanced as credit to rural borrowers to solve the problem of inadequacy of credit to rural based small-scale industries.

- The Nigerian Agricultural and Co-operative Bank (NACB). The NACB was established in 1972 to assist in financing viable agricultural projects and thus enhance the level and quality of agricultural production.

- The Nigerian Bank for Commerce and Industry (NBCI). It was established by Decree 22 of May 1973 and charged with the function of providing equity capital funds by way of loans to small and medium scale industries

- The Agricultural Credit Guarantee Scheme Fund (ACGSF). The Agricultural Credit Guarantee Scheme Fund (ACGSF) was established in 1977 and it took off in April 1978 under the management of the CBN, while a Board of Directors was constituted for policy making. The scheme was designed to encourage banks to increase lending to the agricultural sector by providing some form of guarantee against risks inherent in agricultural lending. In case of default, the lending banks is expected to exhaust all legal means of loans recovery, including realisation of any security pledged for loan, before the ACGSF pays $75 \%$ of guaranteed loans in default.

- The National Economic Reconstruction Fund (NERFUND). NERFUND was set up by Decree No. 25 of 1988 as a funding mechanism aimed at bridging the gap in the provision of local and foreign funds to small and medium scale enterprises. The federal government set it up to provide relatively long-term loans (5-10 years) to small and medium scale enterprises at relatively concessionary rates of interest.

- People's Bank of Nigeria. The People's Bank of Nigeria (PBN) was established by the Federal Government in 1988 with an initial take-off grant of N30 million to meet the credit needs of small borrowers who cannot satisfy the stringent collateral requirements normally demanded by conventional banks. The bank was designed to cater for the credit needs of informal sector operators such as artisans and petty traders' in both the urban and rural areas and thereby increase their self-reliance.

- Community Banks (CBs). These were established in 1990 with the objectives of providing effective financial services for the rural areas as well as micro-enterprises in the urban centres. Community banks in Nigeria were self-sustaining financial institutions owned and managed by local communities such as community development associations, town unions, cooperative society's, farmers' groups, social clubs, etc to provide financial services to the respective communities.

- The Small and Medium-Scale Enterprises (SME) Apex Unit Loan Scheme. To increase access to credit by the SMEs, the CBN and the Federal Ministry of Finance, on behalf of the Federal Government, obtained a World Bank Loan for SMEs. The total project cost was US\$451.8 million, of which the World Bank provided US $\$ 270$ million or $64 \%$. The CBN established an SME Apex Unit in the Bank in 1990 to administer the credit components and other related activities of the World Bank loan to facilitate project implementation. Loans disbursement under the Scheme ceased in 1996.

- Nigerian Export-Import Bank (NEXIM). The Nigerian Export Import Bank (NEXIM) was established by Decree 38 of 1991 to manage several credit facilities introduced specifically to boost Nigeria's non-oil export sector. The bank commenced operations on 2nd January 1991 with facilities in the following areas: trade finance, project finance, treasury operations, export advisory service, and market information.

- The Nigerian Agricultural, Cooperative, and Rural Development Bank (NACRDB), now Bank of Agriculture (BOA). The bank was set up in October 2000 as an amalgam of the old Peoples Bank of Nigeria (PBN), Nigerian Agricultural and Cooperative Bank (NACB) and Family 
Economic Advancement Programme (FEAP). It is jointly owned by the Federal Ministry of Finance Incorporated (MOFI) and the Central Bank of Nigeria (CBN) with a shareholding ratio of 60 and $40 \%$ respectively. The primary aim is to finance agriculture as well as small and medium enterprises. While micro credit facilities account for $70 \%$, the balance of $30 \%$ is for macro-credit facilities.

- The Bank of Industry (BOI). This is also an amalgam of the former Nigerian Industrial Development Bank (NIDB), the Nigerian Bank for Commerce and Industry (NBCI) and the National Economic Reconstruction Fund (NERFUND). It was set up in 2000 principally to provide credit to the industrial sector. The mandate of the BOI include providing financial assistance for the establishment of large, medium, and small projects; as well as expansion, diversification and modernization of existing enterprises; and rehabilitation of ailing industries. The percentage of its annual lending to MSMEs increased to $96 \%$ by December 2010 from 35\% in 2005 [28].

- Small and Medium Enterprises Equity Investment Scheme (SMEEIS). Bothered by the persistent decline in the performance of the Industrial sector and with the realization of the fact that the small and medium scale industries hold the key to the revival of the manufacturing sector and the economy, the Banker's Committee in 1999, initiated the Small and Medium Industries Equity Investment Scheme (SMIEIS) aimed at ensuring assistance to small-scale industries. Under this new scheme, banks are required to set aside $10.0 \%$ of their profit before tax for investment in small-scale industries in the country. A bank's investment in the scheme is conceived to be in the form of equity participation, project packaging/monitoring, advisory services and nurturing of specific industries to maturity. The SMIEIS was named Small and Medium Equity Investment Scheme (SMEEIS) in March 2005 , to broaden the scope of activities that can be funded under it.

\subsection{Procurement Mandates}

At the national, state, and local levels, government actors initiate procurement policies, which require a certain percentage of goods and services to be provided by specific types of businesses - and many of these policies are for small businesses.

Advantages

Large Purchasing Power of Governments. At the very least, targeting small businesses to supply a significant amount of demand for goods and services can help sustain them.

Disadvantages

Standards Not Always Met. Even though the government sets goals or standards as part of a policy, this does not ensure they'll be reached.

The full potential of procurement policies' impact on supporting small businesses can be unknown.

Lack of Data. The intent of these policies is to grow and create jobs, however, there is a lack of measurable data that assesses these outcomes.

Anchor Borrowers Programme. The Anchor Borrowers Programme is aimed at creating economic linkages between over 600,000 smallholder farmers and reputable large-scale processors with a view to increasing agricultural output and significantly improving capacity utilization of integrated mills. The Central Bank of Nigeria had set aside N40 billion from the N 220 billion Micro, Small and Medium Enterprises Development Fund for farmers at a single-digit interest rate of 9 per cent.

\subsection{Business Incubators}

Business incubators provide counselling, networking, training, and technical assistance services to small businesses/entrepreneurs, yet they differ from other business creation strategies in a central aspect: the incubator manager and staff along with the businesses are co-located in the same facility [29]. Business incubators usually receive funding from academic institutions, economic development and/or other types of organizations, for-profit companies, and also government entities, which sponsor up to $20 \%$ of incubators. Government assistance for incubators can occur through tax abatements, local funding, and subsidies.

The overarching goal of incubators is to foster business development of knowledge, competencies, and resources that lead to independent, self-sustaining businesses. 


\section{Advantages}

Supports Job Creation. Many incubators are designed to help foster the creation of companies in new technologies and industries. To the extent that the incubator is supporting the development of new markets, the jobs created will be net new ones.

Creates Jobs in Low-Income Areas. Research suggests that business incubators create new jobs in inner cities, however it isn't clear how many are net new jobs or simply relocation of jobs [29].

Provides Valuable Support for Growing Small Businesses [30]. The colocation of both the incubator and businesses fosters a unique supportive environment where personnel and infrastructure support is provided on a daily basis, such as: shared business services (administrative work, janitorial, security, etc.), use of equipment (computers, phones, fax machine, etc.), and facilities (lunch room, meeting rooms, etc.), information networking, and exchange of ideas with other entrepreneurs, all of which can lower transaction costs for new companies. This can foster job creation or retention if increasing transaction costs limit businesses' ability to hire and/or forces them to decrease their size of employment.

\section{Disadvantages}

Mismatch Between Resources Provided and Clients'. Not all start-up companies are the same and can require very different types of resources. To ensure a better success rate for businesses, incubators must admit companies with mutual objectives and require the specific support services provided. If not, incubators will need to specialize in different resources to properly meet their clients' needs.

May Not Serve Every Business Type. If diversity is lacking among incubator programs, this model can only adequately serve specific businesses.

Lack of Competitiveness. It may be difficult for firms to differentiate themselves from competitors if they share access to the same resources.

\subsection{Green Jobs Strategies}

It is widely held that investments in building a clean energy ("green") economy in Nigeria will result in employment gains and other benefits. The Centre for American Progress estimated that a $\$ 100$ billion green recovery program featuring investments in several energy efficiency and renewable energy strategies - retrofitting buildings, developing mass transit systems, producing and utilizing alternative fuels and energy sources, and constructing "smart grid" systems - would translate into two million new jobs within two years [31]

There is general agreement that the pace of green job creation is likely to accelerate in the years ahead (World Watch Institute. 2008a). For this reason, and because green jobs programs have the potential to address dual goals of job creation and environmental sustainability, "green jobs" are increasingly targeted in local economic development efforts.

Despite the widespread usage of the term "green jobs," there is no consensus about what these jobs are. Various parties, including environmental and workforce advocates, labour market economists, workforce development professionals, and other stakeholders have defined "green jobs" differently.

\subsubsection{Current and potential green jobs}

The varying definitions make it difficult to evaluate the relative employment effect of green jobs programs. Various parts of the green economy generate distinct combinations and numbers of green jobs. Depending on the situation, employment outcomes include:

- Job creation in new, "green" fields (e.g., energy auditors or fuel-cell developers);

- Employment substitution (e.g. shifting from mining coal to creating bio-fuels;

- Transformation or redefinition of existing jobs, especially in construction industries, as workmethods and profiles are greened; and

- Elimination of some jobs without direct replacement.

\subsubsection{Strategies for creation and development of green jobs}

States and cities utilize several general strategies to create and develop green jobs. Strategies include (among others):

- The adoption of policies to promote demand for renewable energy and energy-efficient goods and services; 
- The use of financial incentives for energy efficiency, and the establishment of "green" or energyefficient programs and standards for new and existing buildings;

\subsubsection{Policies}

Nigeria can adopt renewable portfolio standards or targets that require electricity providers to supply a minimum amount of power from renewable energy sources. Energy efficiency standards for energy generation, transmission and use are also recommended. Public sector entities also should develop regulations that require adherence to green standards and practices, often use rating systems that prioritize compliance with these standards when awarding public contracts.

Research suggests that such policies will lead to creation of new jobs. For example, the UC-Berkeley's Vial Centre for Employment in the Green Economy study projects that by 2020, energy efficiency policies will result in about $\$ 11.2$ billion of public and private investment, resulting in 211,000 jobs in California [32].

\section{Advantages}

Incentives for New Products and Methods. The need to meet standards and targets creates incentives for both the private and public sectors to develop and export new technologies, infrastructure, products, and processes, which can reduce reliance on imports and may lead to business expansion and employment gains. Incentives for public and private sectors to use green products, services, technologies, and processes can result in contracts for green businesses, which could result in business growth and additional hires.

Builds Awareness. Policies build awareness of environmental quality issues, which may increase market demand for green products and services. Jobs can be created as firms raise production, or as new businesses are created to meet the demand.

\section{Disadvantages}

Cost Increases. Regulations and standards can result in cost increases, which could put businesses at a competitive disadvantage. Costs of products and services could rise.

Regulatory Expenses. The legal and administrative costs of developing policies, standards, and enforcement procedures may increase public costs in the short term.

\subsubsection{Financial incentives}

Every state in Nigeria should offer some form of financial incentive to drive its clean energy economy. The states can provide residential, commercial and industrial loan financing for the purchase of renewable energy or energy efficiency systems or equipment. They can also offer rebate programs to promote the installation of renewable energy systems and energy efficiency measures such as solar water heating and photovoltaic systems. Furthermore, the states can offer some form of tax incentive to encourage residents and corporations to use renewable energy or adopt energy efficiency systems and equipment. Finally, the states can offer subsidized weatherization programs for low-income customers.

\section{Advantages}

Expanded Markets. Develops markets for green products and services, which can lead to job creation. Weatherization programs and energy efficient installations increase demand for workers to install systems, products, or new materials, thus creating jobs that were not previously available.

New Businesses. Build clean energy support services, which helps develop local clusters and reduce dependence on imports.

\section{Disadvantages}

Requires investment. Initial costs for products, systems, and equipment can be high.

Administrative Costs. Rebate and incentive program administration costs for agencies and businesses receiving incentives can reduce overall impact. The costs of permitting, inspection, and accounting can be prohibitive.

\section{$5 \quad$ Worker-Based Strategies}

In this section, we start with the basic assumption that labour supply greatly exceeds labour demand in the Nigerian labour market today. Workers with lower educational attainment levels and workers from low income communities have also been particularly hard-hit in this recession, facing higher-thanaverage unemployment rates. 
This disparity may be surprising to some at first. According to job chain theory, any new job created in a local economy will eventually "trickle down" to provide new and better economic opportunities for those at the lowest rungs of the economic ladder. When new jobs are created, people advance into them from lower down on the job chain, and so on throughout the chain until new job openings reach workers at the base of the ladder. However, this theory has been widely criticized for not recognizing that a gap exists in this job chain in which unskilled workers at the very base of the ladder find few opportunities to move up the ladder because they lack a certain level of formal education or job skills [33].

So, if we accept the data that current high rates of unemployment are disproportionately concentrated within low-income communities and if we further reject the claims that new high-skill jobs will trickle down to create new jobs at the lower rungs of the economic ladder, then this discussion about job creation must specifically address strategies to make jobs accessible to disadvantaged workers. Just taking the macro-economic perspective that any net new job will help workers is not enough. We not only have to grow the pie; we also must address how it's getting divided up.

While this imperative can be justified from several perspectives, we would argue primarily that targeting disadvantaged workers as suggested is an excellent way to (1) counteract what most accept to be growing income inequality in Nigeria and (2) thereby stabilize the economy. Labour market scholars point to the growing income inequality of the last 40 years as a root cause of why this current economic recession has been so long and deep. Turning this trend around and increasing both job opportunities and job quality for disadvantaged workers could have profound impacts in providing long-term economic stability.

Finally, we think it's important to look at job creation in terms of the duration of the job (job years) and its quality (wages, benefits, and skills development). While it could be argued that any new job can create work experience and is thus valuable, the skills developed in short-term, low quality jobs are not particularly useful if there are no long-term, high-quality jobs in which to apply them. Thus, in our view, job creation is less about creating just any new job and more about creating long-term, high-quality jobs that raise households and communities out of poverty.

Below is a review of policies and strategies that specifically target improving job opportunities in communities that face barriers to employment. This includes both labour demand-side strategies to increase job accessibility and strategies that improve the quality of jobs that are already accessible to disadvantaged workers. These strategies focus on actions that policy-makers can take.

\subsection{Local Hire and First Source Hiring Laws}

Local hire and first source hiring laws are policies that commit an employer to hire a certain percentage of their workforce from a specific pool of applicants. The target population can be a resident of a certain neighbourhood where the new jobs will be located. More recently, there have been successful attemptsin the Niger Delta region of Nigeria - for oil firms to hire a percentage of the indigenes, regardless of where the job is located within the area. The target population can also be workers who have received certain training or gone through a specific training program. Oftentimes, these policies are included as a part of Community Benefits Agreement tied to a specific large-scale development.

Local hire and first source policies can apply to both temporary and permanent jobs. Temporary jobs include construction jobs like carpentry, plumbers, steelworkers, gutter clearing, etc. These jobs are often well-paid, union jobs that do not require much more than a high school level of education, making them important pathways to the middle class for many workers with lower levels of formal education. Permanent jobs can provide long-term job security, but will often be in the retail, restaurant, or hotel industries, which are notoriously low-paying and low-benefits occupations.

\section{Advantages}

Effective. In many situations, local hire laws have proven to be effective in increasing job accessibility for disadvantaged workers by increasing the demand for workers from a certain area or a certain demographic.

Legally Viable. There is a growing body of case law around local hire that suggests it is an appropriate legal tool if it does not apply to out-of-state workers. This makes local hire one of the few policies that can legally target disadvantaged workers [34]. 


\section{Disadvantages}

Difficult to Implement. Though many of these policies look great on paper, communities struggle with implementation and enforcement of them. The governing jurisdiction rarely tracks hiring records to ensure compliance, and often relies on "good faith" measures that are difficult to enforce even when there is political will to track compliance.

\subsection{Wage Increases-Minimum}

Wage increases generally in minimum wage increases set at the state or federal level; in Nigeria, the minimum wage is $\mathrm{N} 18,000$ per month.

\section{Advantages}

Direct Benefit to Households that Need It. Wage increases provide the most direct and instant benefit to the working poor and underemployed, as well as their family network in the form of increased household wages. Thus, even if a wage increase does not lead to higher employment levels, it could benefit households and communities that have high unemployment rates indirectly by raising the incomes of households that have at least one employed family member.

\section{Disadvantages}

Indeterminate impact on job creation. Both economic theory and empirical research are ambivalent on the net jobs impact of wage increases. While some research has pointed to a net decline in overall employment due to minimum wage increases, other studies find no impact. The impact seems to be neutral at best $[35,36]$.

\section{Conclusion}

\section{Job Creation Is More Important than Ever.}

The job creation strategies outlined here reflect the wide range of approaches that can be utilized to increase the levels and quality of employment across Nigeria. The effectiveness of each approach depends on the extent of alignment with community needs, strengths, and capacities; the presence of supportive policies; and the availability of funding and resources necessary for implementation. In many cases, multiple strategies and interventions are required to achieve desired results.

The recent "Recession" has demonstrated the difficulty of creating new jobs when unemployment is high. In times like these, decision makers face the additional challenges of differentiating between longand short-term goals to select the policies and practices that will best meet their needs. Now, more than ever, there is a critical need for decision-makers to identify the effective strategies that should be implemented to grow the 8.8 million jobs lost and to rebuild the economy.

Our hope is that the way we organized the various job creation strategies discussed in this paper-by four basic themes - allows for easy reference and provides a useful conceptual framework for those weighing job creation strategies. Further, we hope that the discussion of advantages and disadvantages with respect to each strategy better informs decisions as to which approaches align best with public priorities and desired outcomes. Finally, we hope that we have conveyed the dire need for more, and better, evaluation of job-creation strategies-particularly the need to identify the quality and sustainability of the jobs they maintain and create. Where this information is lacking, decision-makers will be at a distinct disadvantage.

\section{References}

1. Z. G. Alemu. "The Challenge of Job Creation in Nigeria", Chief Economist Complex | AEB Volume 6, Issue 8, 2015

2. J. Rothstein, Interview. "Job Tax Credits and Job Creation". IRLE Job Creation and Local Communities Speaker Series. Feb 23, 2011.

3. K., Jacobs, L. Lucia, and T. W Lester, "Regional Economic Impacts of Proposed Health and Human Services Cuts. CLRE Policy Brief", 2010.

4. Jacobs, Ken. Interview. May 4, 2011. 
5. R. Pollin, and D. Baker, "Reindustrializing America: A Proposal for Reviving U.S. Manufacturing and Creating Millions of Good Jobs." New Labor Forum 19, 2: 16-34, 2010

6. L. Levine, Job Growth During the Recovery. Congressional Research Service, 2010. Retrieved http://assets.opencrs.com/rpts/R41434_20100930.pdf

7. J. Fitzgerald, and N. G. Leigh, Ch. 1 "Redefining the Field of Local Economic Development" in Economic Revitalization: Cases and Strategies for City and Suburbs. Thousand Oaks, CA: Sage Publications 2002.

8. T. J. Bartik, "Local Economic Development Policies." Upjohn Institute Working Paper No. 03-91. Kalamazoo, MI: W.E. Upjohn Institute for Employment Research 2003. Retrieved http://research.upjohn.org/up_workingpapers/

9. M. Anderberg, "Job Chains: Theory and Practical Implications for Workforce and Economic Development." Beyond the Numbers: Labor Market Information Research and Writings. September 2006.

10. L. Zheng, "Trapped in the Race to the Bottom: Who is Using Business Incentives Now?" Dept. of City and Regional Planning, Cornell University 2009.

11. M. L. John, "What Economic Developers Actually Do." Journal of the American Planning Association 56,2, 1990.

12. A. Markusen, and K. Nesse, "Institutional and Political Determinants of Incentive Competition" in Markusen, A., ed., Reining in the Competition for Capital 2007.

13. J. Fitzgerald, and N. G. Leigh, "Industrial Retention: Multiple Strategies for Keeping Manufacturing Strong," in Economic Revitalization: Cases and Strategies for City and Suburbs. Thousand Oaks, CA: Sage Publications 2002.

14. T. J. Bartik, "Solving the Problems of Economic Development Incentives" in Markusen, A., ed.. Reining in the Competition for Capital, Kalamazoo, MI: W.E. Upjohn Institute for Employment Research, pp.103-140, 2007.

15. T. J. Bartik, "The Revitalization of Older Industrial Cities: A Review Essay of Retooling for Growth." Upjohn Institute Working Paper No. 08-143. Kalamazoo, MI: W.E. Upjohn Institute for Employment Research, 2008

16. Small and Medium Enterprises Development Agency of Nigeria (SMEDAN), "National Policy on Micro, Small and Medium Enterprises". Federal Republic of Nigeria, SMEDAN, Abuja, Nigeria, January, 2007.

17. Harrison, Bennett. 1994. "The Myth of Small Firms as the Predominant Job Generators." Economic Development Quarterly 8: 3.

18. D. Neumark, B. Wall, and J. Zhang, "Do Small Businesses Create More Jobs? New Evidence for the United States from the National Establishment Time Series." The Review of Economics and Statistics 93,1: 16-29, 2011.

19. B. Fuller, L. Pantuosco, D. Parker, and D. Keith Robbins "An Empirical Assessment of the Contribution of Small Business Employment to U.S. State Economic Performance." November 2000. Small Business Economics 15: 293-302, 2000.

20. Central Bank of Nigeria, Research Department, The changing structure of the Nigerian economy and implications for development. Lagos: Realms Communications Ltd, 2000

21. CBN/FOS/NISER, A study of Nigeria's informal sector, Volumes 1 and 2, September, 2001

22. B. I Adamu, Financing gap for small and medium enterprises in post consolidated banking sector in Nigeria. Bullion, Central Bank of Nigeria. 33.3. July-September: 38-53, 2009.

23. O. E. Essien, 2001. The role of development finance institutions in the financing of small-Scale industries. Bullion, Central Bank of Nigeria. 25.3 July/Sept.

24. S. I., Owualah, Do Nigerian SMEs Face Equity or Credit Gap Problems? Nigerian Economic Summit Group (NESG) Economic Indicators, 2002.

25. C. M. Anyanwu, B. S. Adebusuyi and B. O. N. Okafor, The Slow Pace of Disbursement of the SMIEIS and Need for Remedial Measures. Central Bank of Nigeria Occasional Paper No.30, 2003.

26. V. O. Akinyosoye, Plant Size and Factor Productivity in Agro-allied Industries: Implications for Nigeria's New Industrial Policy. Journal of Rural Economics and Development, Vol.15, No.2, 2006.

27. M. Adelaja, "Microfinance as a Tool for Building and Enhancing Capacities in the Informal/SME Sectors of the Economy". Paper presented at the Workshop Organized by Poultry Association of Nigeria, Lagos Chapter, at the Events Centre, Alausa, Lagos, 2007.

28. Bank of Industry,. Delivering on our Mandate. Special Edition, March, 2011.

30. M. Rice, L. Peters, and M. Sundararajan, "The Role of Incubators in the Entrepreneurial Process." The Journal of Technology Transfer 29, 1: 83-91, 2004

31. R. Pollin, et al. "Green Recovery: A Program to Create Good Jobs and Start Building a Low-Carbon Economy." Center for American Progress; Political Economy Research Institute, University of Massachusetts, Amherst, 2008. 
32. Zabin, et al. "California Workforce, Education, and Training Needs Assessment for Energy Efficiency, Distributed Generation and Demand Response." Vial Center for Employment in the Green Economy, University of California, Berkeley, 2009.

33. M. Andberg, "Job Chains: Theory and Practical Implications for Workforce and Economic Development" in Beyond the Numbers: Labor Market Information Research and Writings, 2006.

34. B. Reagan, Presentation. "Community Benefits and Accountable Development". IRLE Job Creation and Local Communities Speaker Series. April 18, 2011.

35. D. Card, and A. B. Krueger, "Minimum Wages and Employment: A Case Study of the Fast Food Industry." American Economic Review 84, 4: 772-793, 1994

36. Dube, Arindrajit, T. William Lester, and Michael Reich. "Minimum Wage Effects Across State Borders: Estimates Using Contiguous Counties." The Review of Economics and Statistics. 92:4 (2010): 945-964.

37. World Watch Institute. 2008. "Green Jobs-Towards Decent Work in a Sustainable, Low-Carbon World." 